\title{
"AGORA SEU FILHO ENTRA MAIS CEDO NA ESCOLA": A CRIANÇA DE SEIS ANOS NO ENSINO FUNDAMENTAL DE NOVE ANOS EM MINAS GERAIS
}

\author{
Lucíola Licínio de Castro Paixão Santos \\ Lívia Maria Fraga Vieira**
}

\begin{abstract}
RESUMO: Pela Lei federal 11.274/2006, promulgada em 6 de fevereiro deste ano, o ensino fundamental no Brasil passa a ter a duração de 9 anos, com a inclusão das crianças de 6 anos de idade. No entanto, alguns municípios e estados se anteciparam a esta lei, pois antes de sua promulgação já haviam estendido a obrigatoriedade escolar, a partir dos 6 anos, passando o ensino fundamental a ter um ano a mais de duração. Este é o caso de Minas Gerais que, em 2004, instituiu o ensino fundamental de 9 anos, incluindo as crianças de 6 anos de idade. Neste contexto, este artigo busca mostrar como foi implantado o ensino fundamental de 9 anos em Minas Gerais, considerando a realidade educacional brasileira. $\mathrm{O}$ objetivo é fazer uma análise sobre esta medida e identificar que condições possibilitaram sua emergência e as conseqüências de sua implementação para o ensino fundamental e para a educação infantil. Nesse sentido, considera-se a necessidade de discutir os efeitos de uma política em suas interaçôes com outras políticas. Para isso, busca-se não endossar apenas os efeitos positivos mais aparentes e também não aderir apressadamente às críticas até então levantadas sobre esta política.
\end{abstract}

Palavras-chave: Ensino fundamental de nove anos em Minas Gerais. Crianças de 6 anos no ensino fundamental. Nova organização do ensino fundamental.

\footnotetext{
* Pós-doutora em Educação pela Universidade de Londres e professora do Departamento de Administração Escolar da Faculdade de Educação da Universidade Federal de Minas Gerais (UFMG). E-mail: luciola@netuno.lcc.ufmg.br

** Doutoranda em Educação pela Universidade de Paris V e professora do Departamento de Administração Escolar da Faculdade de Educação da UFMG. E-mail: liviafraga@globo.com
}

Educ. Soc., Campinas, vol. 27, n. 96 - Especial, p. 775-796, out. 2006

Disponível em <http://www.cedes.unicamp.br> 
"Agora seu filho entra mais cedo na escola": a criança de seis anos no ensino fundamental...

"NOW YOUR CHILD GOES TO SCHOOL SOONER" SIX-YEAR OLD CHILDREN IN THE NINE-YEAR-LONG BASIC EDUCATION IN Minas Gerais

ABSTRACT: Approved in February $6^{\text {th }}, 2006$, Law 11274/2006 extends the Brazilian basic education to nine years, by also enrolling six-year-old children. However, some municipalities and states did so even before this federal act was approved. This is the case of the state of Minas Gerais. This paper shows how this policy has been implemented there. It analyzes this law implementation process trying to identify the conditions for its approval and the consequences on basic and early childhood education. Since the effects of an educational policy in connection to other public policies have to be discussed, this text tries not only to ratify its apparently positive effects but also to look carefully at the critics against it.

Key words: Nine-year-long basic education in Minas Gerais. Six-year old children in basic schools. Basic school new organization.

que era para poucos agora é para todos". Com esse slogan o governo do estado de Minas Gerais anunciou, em agosto de 2003, a abertura do cadastramento escolar para o ano de 2004. Duas novidades: o cadastro para o início do ensino fundamental incluía a criança de 6 anos; o ensino fundamental foi estendido para uma duração de nove anos. Não se tratava tão somente de uma antecipação da escolaridade, mas de aumento da obrigatoriedade, fazendo-se acompanhar de uma reforma pedagógica. Assim, a novidade reside menos na entrada da criança de 6 anos e mais na extensão do tempo, com a intenção manifesta de repensar a cultura pedagógica da alfabetização no ensino fundamental e reverter resultados negativos evidenciados nas avaliaçōes do Sistema Mineiro de Avaliação da Educação Pública (SIMAVE) e do Sistema Nacional de Avaliação da Educação Básica (SAEB). Isto pode ser inferido pela análise dos instrumentos legais e das orientações oficiais produzidos para implementação das medidas, pelas estratégias midiáticas utilizadas para sua divulgação, ${ }^{1}$ como também pela convergência de decisões sobre o assunto nos planos federal e municipais de governo.

Um estudo sobre a ampliação do ensino fundamental, ainda que preliminar, no âmbito de uma unidade federativa é o que busca realizar este artigo, baseando-se na leitura de documentos oficiais e de legislação, depoimentos de dirigentes da educação e especialistas, na 
produção da imprensa falada e escrita e nas informações estatísticas demográficas e educacionais. Também são levados em conta o contexto nacional e as políticas federais concernentes. As razões implícitas e explícitas para a adoção dessa política são destacadas, buscando-se mostrar que a sua aprovação e implementação não são objeto de consenso na área educacional. Apresentando posiçōes diferenciadas, o campo da educação infantil tem levantado discussões sobre o tema, no âmbito dos encontros anuais do Movimento Interfóruns de Educação Infantil do Brasil (MIEIB) e da Associação Nacional de Pós-Graduação e Pesquisa em Educação (ANPEd). Finalmente, são ressaltados alguns elementos para a análise e o acompanhamento dessa política.

\section{Educação fundamental de nove anos em Minas Gerais}

O aumento do tempo de ensino obrigatório foi uma decisão governamental que angariou simpatias da população, sobretudo das famílias imediatamente envolvidas, gerando adesōes e expressões de defesa, bem como argumentações favoráveis. ${ }^{2}$ Ao agregar o denominado terceiro período da pré-escola no ensino fundamental, foi divulgado ser Minas Gerais o primeiro estado brasileiro a assumir tal medida na sua rede de ensino.

Segundo o secretário adjunto de Educação do estado de Minas Gerais, professor João Antônio Filocre Saraiva, ${ }^{3}$ duas razões sustentaram essa decisão. A primeira delas diz respeito à necessidade de aumento do sucesso escolar das crianças provenientes das camadas populares. João Saraiva argumentou que a literatura educacional mostra que o melhor desempenho escolar das crianças das classes médias pode ser atribuído, dentre outros fatores, à precocidade da idade de ingresso no sistema escolar. Dessa maneira, a inclusão das crianças de 6 anos no ensino fundamental visa oportunizar às crianças das escolas públicas, geralmente provenientes dos setores de mais baixa renda da população, maior igualdade na idade de acesso à educação escolar. A segunda razão destacada está associada à disponibilidade criada na rede estadual, em termos de salas vagas e de professores sem classes. Tal cenário é resultado tanto da diminuição das matrículas no ensino fundamental, decorrente da queda na taxa de fecundidade no país (especificamente no estado de Minas Gerais, cuja taxa média é um pouco menor que a média brasileira), ${ }^{4}$ como também é decorrente do processo de municipalização 
"Agora seu filho entra mais cedo na escola": a criança de seis anos no ensino fundamental...

da pré-escola e das primeiras séries do ensino fundamental. Estes dois fatores provocaram uma ocupação média de 0,8 dos prédios escolares estaduais e um excedente de cerca de 13 mil professores sem classes. Estes dois fatores, segundo João Saraiva, reduziram a tal ponto a matrícula no ensino fundamental estadual que nem mesmo a inclusão das crianças de 6 anos neste nível de ensino foi suficiente para ocupação das vagas potenciais, que estão sendo preenchidas com a institucionalização gradativa do ensino em tempo integral.

Ainda segundo João Saraiva, a universalização do ensino das crianças de 6 anos no estado de Minas Gerais teve início em 2004. ${ }^{5}$ As crianças que ingressaram naquele ano foram avaliadas em 2005 e os resultados desta avaliação mostram que $67 \%$ aprenderam a ler e escrever com 6 anos de idade.

Experiências dessa natureza não são, no entanto, novidade na rede pública de ensino. Há dez anos, alguns municípios incluíram as crianças de 6 anos no cadastro para o ensino fundamental. Isto ocorreu na rede municipal de Belo Horizonte em 1994, quando esta medida foi anunciada no contexto da implantação das reformas estabelecidas pelo projeto "Escola Plural". Esta reforma também instituiu os ciclos de formação, substituiu a seriação e gradativamente foi incorporando ao ensino fundamental as crianças de 6 anos, absorvendo todo cadastro desta faixa etária, a partir de 1999. Atualmente, com o cadastro escolar unificado ${ }^{6}$ (rede municipal e estadual), os alunos são inscritos para a matrícula na rede pública de ensino no mês de junho, sendo consideradas com direito ao cadastramento as crianças que completam 6 anos neste mês. ${ }^{7}$

Segundo a secretária municipal de Educação de Belo Horizonte, Maria do Pilar L. Almeida e Silva, alguns efeitos da inclusão de alunos de 6 anos na rede municipal já podem ser percebidos. Destacou a construção de espaços de recreação, como os chamados parquinhos infantis, que terminam sendo utilizados por crianças de diferentes faixas etárias. Salientando a importância do lúdico na educação das crianças, na sua visão, estas iniciativas (que se disseminaram progressivamente após a inclusão das crianças de 6 anos no ensino fundamental) atestam conseqüências positivas da ampliação da idade escolar, modificando práticas pedagógicas no primeiro ciclo da educação fundamental. Segundo a secretária, as professoras se defrontaram com as necessidades e especificidades da educação da infância, passando a considerá-las em sua prática pedagógica, criando também novas necessidades para a formação docen- 
te. Isto contribuiu para consolidar a educação do ciclo da infância no ensino fundamental do município de Belo Horizonte.

Mesmo assim, a decisão anunciada pelo governo do estado ganha notoriedade pela dimensão da rede estadual de ensino em Minas ${ }^{8}$ e pelos possíveis e prováveis impactos nas redes municipais de ensino fundamental e de educação infantil. Sabe-se que tais medidas mobilizam dirigentes, professores e famílias, suscitam inúmeras dúvidas e entendimentos diversificados, de acordo com o lugar que os sujeitos ocupam, não sendo desprezível o seu efeito indutor de ações e decisões nas redes de ensino municipais e o seu impacto na organização das idades no ensino fundamental e na educação infantil.

O processo de implementação, além dos problemas de infra-estrutura, de currículo e formação docente, torna-se mais complexo, devido ao processo de apropriação, pelos sujeitos envolvidos, dos significados desta política, ou seja, a interpretação dos dispositivos legais não é unívoca. Este fato é evidenciado por depoimentos colhidos em seminários e encontros com dirigentes e professoras, sejam da rede estadual, sejam das redes municipais de ensino, em Minas e em todo o país, onde várias das questôes e dúvidas são levantadas, merecendo, além de respostas, reflexão e pesquisa. ${ }^{9}$

\section{Razões que levaram à decisão e implementação}

Razões demográficas: diminuição das taxas de fecundidade, resultando em menos alunos no ensino fundamental, gerando capacidade ociosa na rede física escolar e professores excedentes. Isto não exclui a necessidade, segundo os depoimentos coletados, de readequaçóes e investimentos, pois é preciso considerar as desigualdades regionais e de renda no acesso à creche/pré-escola e escola, que resultam na existência de áreas que apresentam menores índices de escolaridade de crianças de 5 e 6 anos. Em geral, são as regiōes e áreas de maior concentração de pobreza, menores taxas de urbanização e maiores taxas de fecundidade.

Razôes financeiras: o investimento na criança de 6 anos foi mais compatível com os recursos disponíveis do que estender a obrigatoriedade para o final do ensino fundamental, com a inclusão de estudantes que estão ou deveriam estar no primeiro ano do ensino médio. Os professores excedentes seriam mais dificilmente assimilados nas séries finais do ensino fundamental ou no ensino médio. 
"Agora seu filho entra mais cedo na escola": a criança de seis anos no ensino fundamental...

Razôes políticas: a previsão de que haveria uma recepção positiva da medida, sobretudo por parte das famílias mais pobres, devido à demanda por educação da criança pequena, principalmente daquelas com idade mais próxima da escola obrigatória. Soma-se a isso a existência de possibilidades de realização imediata da medida, pela disponibilidade financeira e da rede física e o forte apelo de caráter eleitoral que viria a gerar.

Razões pedagógicas ou educacionais: estas razões, sobretudo divulgadas no âmbito do projeto da "Escola Plural" da Secretaria Municipal de Educação de Belo Horizonte, são também apontadas nos documentos do MEC (2004) e na produção da universidade, no contexto dos programas de formação do Ministério da Educação. Tem-se argumentado que: (a) tendo mais um ano, a escola dispóe de um prazo maior para socializar a criança e promover sua inserção num universo cultural novo, criando mais oportunidades de aprendizado; (b) uma parcela maior da população escolar pode se beneficiar das políticas públicas voltadas para a melhoria de ensino fundamental, sendo que municípios e estados, sobretudo os mais pobres, dispõem apenas das linhas de financiamento para este nível de ensino; (c) a entrada mais precoce na escola tem repercussōes positivas na continuidade da escolarização; (d) criam-se melhores condições para a alfabetização das crianças, sendo este considerado um dos problemas históricos da educação brasileira; (e) evita-se que os esforços pela alfabetização, "que se acentuam a partir de seis (às vezes cinco) anos de idade, se dispersem entre a educação infantil e a fundamental" (Batista, 2006, p. 2).

Os documentos do MEC (2004) levantam também a necessidade de dar maior homogeneidade à organização escolar no país, compatibilizando a duração e a idade de ingresso no ensino fundamental, nos sistemas de ensino.

\section{Regulação normativa da implementação e ações de formação}

Para Lascoumes (1990, p. 43), é raro, quase excepcional, que uma nova orientação ou uma mudança na ação pública não seja acompanhada de uma produção normativa específica, sendo isto inerente a todo Estado de direito. O autor considera a definição e a implementação de políticas públicas como um processo de criação normativa continuada e freqüentemente circular. Apesar de ser uma fonte limitada e 
que pode produzir uma história formal da educação, a legislação nos permite conhecer as definições e os princípios diretores de uma política, e perceber a evolução dos motivos da autoridade e das normas pedagógicas resultantes (Luc, 1992).

É nesta perspectiva que se deve analisar a legislação específica produzida pelo governo estadual, e federal, na forma de leis, decretos, resoluçôes, orientações e pareceres. É notável o aumento de consultas junto aos Conselhos de Educação, que também passam a regulamentar sobre o tema, inclusive em resposta às inquietações das situações concretas. ${ }^{10}$

Pretende-se aqui ressaltar apenas os grandes temas tratados na produção normativa específica, que regula a organização e o funcionamento dos anos iniciais do ensino fundamental, com nove anos de duração, nas escolas estaduais de Minas Gerais, expressa nos seguintes instrumentos jurídicos, emanados do executivo estadual: Decreto n. 430, de 7 de agosto de 2003; Resolução n. 469, de 22 de dezembro de 2003; Resolução n. 521, de 2 de fevereiro de 2004; Orientação SEE n. 01/2004, de 5 de fevereiro de 2004, que é uma operacionalização da Resolução SEE n. 469/ 2003.

A Resolução n. 469/2003 detalha aspectos pedagógicos e estrutura o ensino fundamental com duração de nove anos em cinco anos iniciais e quatro anos finais $\left(\right.$ art. $2^{\circ}$ ). Os anos iniciais foram divididos em dois ciclos: o Ciclo Inicial de Alfabetização, com a duração de três anos, e o Ciclo Complementar de Alfabetização, com a duração de dois anos (cap. $3^{\circ}$ ). Permaneceu inalterada a organização do ensino fundamental a partir da quinta série. O Ciclo Inicial, por sua vez, foi subdividido em três fases (cap. $4^{\circ}$ ):

I - Fase Introdutória - destinada aos alunos que ingressarem no ensino fundamental aos 6 anos, completos até 30 de abril de 2004, e aos alunos que completarem 7 anos de idade no período de $1^{\circ}$ de agosto a 31 de dezembro de 2004;

II - Fase I - destinada aos alunos provenientes da Fase Introdutória, após o cumprimento dos objetivos da mesma (correspondendo ao $1^{\circ}$ ano ou à $1^{\text {a }}$ série);

III - Fase II - destinada aos alunos que atingiram os objetivos da Fase I, dando continuidade ao trabalho em desenvolvimento e finalizando os objetivos previstos para o Ciclo Inicial de 
"Agora seu filho entra mais cedo na escola": a criança de seis anos no ensino fundamental...

Alfabetização (correspondendo ao $2^{\circ}$ ano ou à $2^{a}$ série).

O Ciclo Complementar de Alfabetização, dando seguimento ao Ciclo Inicial, compreendeu duas fases: Fase III (correspondendo ao $3^{\circ}$ ano ou à $3^{\mathrm{a}}$ série) e Fase IV (correspondendo ao $4^{\circ}$ ano ou à $4^{\mathrm{a}}$ série).

A necessidade de "revisão das práticas pedagógicas e um cuidado especial em relação aos anos iniciais do ensino fundamental" são ressaltados na Orientação n. 01/2004, que justifica a ampliação do ensino fundamental como uma medida de inclusão. Nela são abordadas questōes relativas à organização dos espaços, dos tempos e das práticas escolares no ciclo inicial do ensino fundamental de nove anos, onde fica evidente a ênfase na alfabetização e letramento, incentivando-se, ao mesmo tempo, a utilização de diferentes linguagens como parte importante do desenvolvimento da criança de 6 anos.

De acordo com a Orientação, cabe ao professor, "mais do que transmitir informações, estimular a criança a (...) desenvolver recursos variados de expressão". E a escola deve propiciar um "ambiente alfabetizador" para as classes de 6 anos, incluindo "diferentes possibilidades para o desenvolvimento de atividades individuais e coletivas (...) como desenhar, pintar etc".

Ao longo do ano de 2004, a Secretaria realizou um conjunto de açóes para divulgar, aprofundar e operacionalizar essa proposta de reorganização dos anos iniciais na rede pública estadual junto aos professores e especialistas de educação. Promoveu reuniōes, seminários e encontros, divulgou orientaçōes pedagógicas e administrativas, produziu materiais didáticos e realizou a aplicação de instrumentos de monitoramento e avaliação. Também realizou estudos internos, reuniōes com as Superintendências Regionais de Ensino (SRE), um seminário e um congresso, focalizando as questôes da alfabetização e da organização dos anos iniciais em ciclos. Outras medidas foram anunciadas para a melhoria do ensino.

Buscando apoiar as escolas, a Secretaria firmou uma parceria com o Centro de Alfabetização, Leitura e Escrita (CEAle/UfMG), que produziu os Cadernos de Orientaçôes para a Organização do Ciclo Inicial de Alfabetização, tendo sido sua primeira versão apresentada e discutida no Congresso Estadual de Alfabetização realizado em Belo Horizonte, em dezembro de 2003, com a participação de 1.500 professores e especialistas das escolas. ${ }^{11}$ 


\section{A extensão do ensino fundamental no contexto nacional}

O Brasil aprovou recentemente a Lei federal n. 11.274, de 6 de fevereiro de 2006, que instituiu o ensino fundamental de nove anos para todos os sistemas, alterando artigos da Lei de Diretrizes e Bases da Educação Nacional (LDBEN). A matrícula neste nível de ensino passa a incluir a criança de 6 anos de idade e foi definido um período de transição de quatro anos, até 2010, quando todas as escolas públicas e privadas deverão se adequar à legislação. Meses antes, em maio de 2005, o mesmo Congresso Nacional havia aprovado a Lei n. 11.114, que instituía a obrigatoriedade escolar para crianças de 6 anos de idade, sem, no entanto, alterar a duração do ensino fundamental, mantendo-a no mínimo de oito anos.

Esta medida concretiza uma das propostas educacionais do governo Lula, que desde 2003 estabeleceu a ampliação da obrigatoriedade escolar para a criança de 6 anos como uma de suas metas (Programa “Toda Criança Aprendendo", 2003). Neste intuito, o Ministério da Educação promoveu, ao longo de 2004, uma série de encontros regionais sobre o assunto, culminando num encontro nacional, além de divulgar orientações quanto à organização das escolas e às propostas pedagógicas (MEC, 2004 e 2006).

No âmbito do Conselho Nacional de Educação (CNE), o debate sobre o tema foi retomado em março de 2004 , sendo o ponto de partida a aprovação da Indicação CNE/CEB n. 1/2004, resultando na aprovação dos Pareceres CNE/CEB n. 6/2005 e n. 18/2005, bem como da Resolução CNE/CEB n. 3/2005, respectivamente em junho, setembro e agosto do ano passado. O primeiro parecer reexamina, por solicitação do MEC, o Parecer CNE/CEB n. 24/2004 e estabelece normas para a ampliação do ensino fundamental de nove anos a partir dos 6 anos de idade. $\mathrm{O}$ segundo parecer tratou das orientaçóes para a matrícula das crianças de 6 anos no ensino fundamental obrigatório, em atendimento à Lei n. 11.114/2005. A Resolução redefiniu as faixas etárias para a educação infantil, crianças até 5 anos, e para o ensino fundamental, crianças de 6 a 14 anos.

É importante destacar que nos últimos dez anos, mesmo antes da promulgação da LDBEN/1996, a discussão de propostas de ingresso de crianças de 6 anos no ensino obrigatório tem ganhado cada vez mais evidência. Tal questão levou o CNE a se pronunciar no Parecer CEB n. 
"Agora seu filho entra mais cedo na escola": a criança de seis anos no ensino fundamental...

20/1998, que respondia consulta feita pela INEP sobre a duração do ensino fundamental. Ao se posicionar favoravelmente à possibilidade de acolher matrículas de crianças de 6 anos no ensino fundamental com duração de nove anos, o Parecer ressalvava que essa medida não deveria resultar numa "disponibilidade média de recursos por aluno da educação básica, na respectiva rede, abaixo da atualmente praticada, de modo a preservar ou mesmo aumentar a qualidade do ensino" e que "nas redes municipais a oferta e a qualidade da educação infantil não sejam sacrificadas, preservando-se a identidade pedagógica".

Embora a extensão do tempo da educação escolar obrigatória tenha sido lenta ao longo do último século, a proposta de inserir crianças menores de 7 anos no ensino fundamental não é nova. Em Minas, ela já era aventada desde 1911, por diretoras dos grupos escolares nascentes da capital. Faria Filho (1995), em trabalho de pesquisa sobre a instrução primária nos primeiros anos da República em Belo Horizonte, buscou verificar como a escola infantil nascente, freqüentada pelos filhos das famílias tradicionais e da elite da capital, era vista pela escola primária. Desde 1908, data de criação do primeiro jardim de infância público, até 1940, Belo Horizonte contava com dois jardins de infância públicos, ambos criados pelo governo estadual.

Segundo Faria Filho, para as diretoras de grupos escolares que atendiam as crianças pobres, a escola infantil era sentida, pela sua ausência. Uma delas, a do $3^{\circ}$ grupo da capital, falava insistentemente no assunto em seus relatórios, tendo como preocupação o baixo índice de aprovação dos seus alunos. Em 1911, esta diretora fez três sugestôes: a primeira era a de abolir o dispositivo do Regimento dos Grupos Escolares, que mandava distribuir os alunos de uma professora faltosa pelas várias outras turmas; na segunda, ela propunha que se exigisse a freqüência mínima legal para que o aluno fosse submetido a exame, o que eliminaria, desde já, os faltosos, obrigando maior vigilância dos pais; na terceira, defendia ou o desdobramento do curso primário em 5 anos ou a criação de escolas infantis em número suficiente para preparar todas as crianças para o $1^{\circ}$ ano do primário.

Impressiona a atualidade desses argumentos e sugestóes. Muitas décadas mais tarde, já nos anos de 1980, a Secretaria de Estado da Educação de Minas Gerais iniciava a implantação do chamado Ciclo Básico de Alfabetização, sendo os dois primeiros anos do ensino fundamental cursados sem interrupção pelos alunos. 
A Lei federal n. 5.692/1971, que instituiu o ensino de primeiro e segundo graus, embora estabelecesse o ingresso no ensino fundamental aos 7 anos de idade, admitia a entrada de crianças de 6 anos, configurando antecipação de escolaridade obrigatória. Dizia o artigo 19 que "para o ingresso no ensino de $1^{\circ}$ grau, deverá o aluno ter a idade mínima de sete anos". No $\$ 1^{\circ}$, entregava-se a cada sistema a competência de elaborar normas que "disporão sobre a possibilidade de ingresso no ensino de primeiro grau de alunos com menos de sete anos de idade".

Ao tratar das possibilidades dessa antecipação, o então Conselho Federal de Educação (CFE) produziu, no período imediatamente posterior à aprovação dessa Lei, um conjunto de pareceres, cuja argumentação dominante, que se transformou em doutrina do órgão, dirigia para a necessidade de uma educação compensatória, antes da escola obrigatória, que teria efeito positivo na reversão do fracasso escolar, pois múltiplas carências estariam na base do insucesso vivenciado por crianças, "privadas de cultura", das camadas populares das periferias das cidades. Concomitantemente, vivia-se intenso processo de adequação das redes de ensino à organização trazida pela nova lei, que, implementando o disposto na Constituição de 1967, ampliava a duração do ensino obrigatório de quatro para oito anos ou séries.

A expansão das matrículas e do acesso no ensino fundamental consolidou-se, no entanto, apenas no final dos anos de 1990, com a forte presença dos municípios na oferta desse nível de ensino. A criação do Fundo de Manutenção e Desenvolvimento do Ensino Fundamental e Valorização do Magistério (FUNDEF), em 1996, teve forte efeito indutor na sua municipalização, engendrando em muitas situações a inclusão de alunos menores de 7 anos, com vistas ao incremento de recursos financeiros. Isto porque mais matrículas resultavam em mais dinheiro, pois, com o FUNDEF, o aluno passou a ter valor monetário (Castro, 2001; Didonet, 1999).

Em que pese os consideráveis avanços no acesso à educação obrigatória, resultantes de políticas que focalizaram (e focalizam) o ensino fundamental, os problemas decorrentes do perfil socioeconômico da maioria da população escolar, e dos aspectos qualitativos do ensino, contribuem para tornar persistentes os altos índices do insucesso escolar, perpetuando desigualdades sociais e mantendo baixo o tempo médio de escolaridade do brasileiro. Recentes resultados de avaliação do Sistema Nacional de Avaliação da Educação Básica (SAEB), divulgados pelo 
"Agora seu filho entra mais cedo na escola": a criança de seis anos no ensino fundamental...

Instituto Nacional de Estudos e Pesquisas Educacionais (INEP), revelaram que $59 \%$ das crianças de 10 anos no ensino fundamental, ou seja, no quarto ano de escolaridade, não sabiam ler e escrever (MEC/INEP, 2003).

Tais indicadores têm reforçado a adoção, pelos sistemas de ensino, de políticas e medidas que articulam conhecimentos acumulados sobre os processos de aprendizagem (ritmos e estratégias infantis) e mudanças na organização e concepção do ensino, tais como os ciclos de formação, classes de aceleração e o privilegiamento de critérios etários para a enturmação no ensino obrigatório. A antecipação do ingresso integra o rol das medidas brevemente mencionadas, com a justificativa de que entrando mais cedo a criança tem mais tempo para aprender e aumenta suas chances de permanência na escola.

A LDBEN de 1996 tratou com flexibilidade a organização do ensino no país. Entre outros exemplos dessa tendência, figurava a definição segundo a qual o ensino fundamental tem duração mínima de oito anos (art. 32) e a opção de matricular crianças de 6 anos neste nível de ensino, de acordo com o parágrafo $3^{\circ}$ do artigo 87 , das Disposições Transitórias.

O Plano Nacional de Educação, ao estabelecer prioridades, coloca em primeiro lugar a garantia do ensino fundamental obrigatório de oito anos a todas as crianças de 7 a 14 anos e a ampliação do atendimento nos demais níveis de ensino, prevendo a extensão da escolaridade obrigatória para crianças de 6 anos.

Apesar da existência de experiências municipais de incluir a criança de 6 anos no atendimento escolar obrigatório, desde meados dos anos de 1990, a produção científica sobre o assunto é ainda muito incipiente. Um breve levantamento, iniciado pelo ano de 1998 até 2003, realizado por nós no Banco de Teses e Dissertações do Portal CAPES, não localizou nenhum trabalho que tratasse do tema, nem de forma correlata.

A legislação, os estudos e os depoimentos coletados para esse trabalho (além da experiência pessoal) permitem concluir que medidas dessa natureza não são de fácil assimilação, pois parecem incidir sobre culturas estabelecidas, sobre expectativas, provocando reações diversas e gerando "efeitos" que precisariam ser conhecidos, previstos, acompanhados.

Nesse contexto, os argumentos levantados no debate sobre a questão reúnem aqueles que apontam problemas e constrangimentos, bem como outros que se posicionam favoravelmente à medida. 
Ao lado dos argumentos favoráveis, já mencionados anteriormente, posicionamentos divergentes estão presentes em diferentes fóruns, tais como o Conselho Nacional de Secretários de Estado da Educação (CONSED), a União Nacional dos Dirigentes Municipais de Educação (UNDIME), Movimento Inter-fóruns de Educação Infantil do Brasil (мIEIB), GT Educação de 0 a 6 anos da ANPEd.

No estado de São Paulo, no município da capital e no governo estadual, essa medida tem sido contestada com o argumento de que se deveria, antes de mais nada, investir na escola de tempo integral. As informaçôes apontam que, na cidade de São Paulo, uma porcentagem elevada de escolas do ensino fundamental ainda funciona em três turnos diários.

No campo da educação infantil, aponta-se a ausência de estudos avaliativos longitudinais do sucesso dos alunos que ingressaram com 6 anos ou de acompanhamento de diferentes práticas de inclusão dos pequenos nos sistemas educacionais brasileiros. "Colocar as crianças das camadas populares no ensino fundamental aos 6 anos sem uma proposta pedagógica adequada significa apenas antecipar o fracasso para elas" (Barbosa, 2003, p. 37).

Uma outra questão que preocupa é a da faixa etária da educação infantil, agora definida para crianças de 0 a 5 anos. Se não se qualifica o 5 e o 6 anos, corre-se o risco de convivermos com diferentes critérios etários para ingresso no ensino fundamental e para a educação infantil. A tendência pode ser de o ensino fundamental "engolir" as crianças mais novas, pela diminuição das matrículas, devida à queda das taxas de fecundidade, como também pela indefinição, até o presente, de fontes de financiamento para a educação infantil.

Subjacente à questão da idade escolar existe outra: Qual é a relação entre os primeiros anos da infância e a educação compulsória? Embora exista uma tendência bem-vinda para a maior cooperação entre a educação infantil e o ensino fundamental, há o risco de que essa cooperação possa levar a uma abordagem "de tipo escolar" na organização das creches e pré-escolas. Para Moss (2004), o risco de domínio por parte da escola compulsória está aumentando: "impulsionados pela competição mundial e pelas avaliações internacionais do desempenho dos alunos, os países cada vez mais se voltam para o período pré-escolar, a fim de 'preparar' as crianças para a escola e para um modelo de transmissão na educação" (p. 44). Para esse autor, a questão não é como 
"Agora seu filho entra mais cedo na escola": a criança de seis anos no ensino fundamental...

os serviços pré-escolares preparam as crianças para a escola, mas se é possível desenvolver uma relação nova e igualitária entre esses serviços. Ou seja, se creches e pré-escolas são "primas pobres" ou sócias igualitárias dos sistemas de educação.

\section{Contribuições para o debate}

Inicialmente, é preciso deixar claro que este artigo não pretendeu fazer uma crítica à extensão do ensino fundamental para nove anos, com a inclusão das crianças de 6 anos. Buscou-se problematizar esta política por diferentes razões. Em primeiro lugar, a literatura no campo da educação vem apontando para a necessidade de se analisar as políticas públicas, considerando seus possíveis efeitos a curto, médio e longo prazos. A este respeito, Ball (1992 e 1994) propõe que as políticas educacionais devem ser analisadas a partir da abordagem do ciclo de políticas, que, apesar de contínuo, apresenta diferentes facetas e arenas que devem ser consideradas nos estudos deste campo. ${ }^{12}$ Neste sentido, este autor advoga a idéia de que o ciclo das políticas públicas deve incluir o contexto dos efeitos ou dos resultados, voltado para a análise do impacto da política que está sendo estudada. Argumenta ainda que, dentro de uma visão mais ampla de uma política, os seus efeitos não podem ser analisados apenas nos seus resultados imediatos, mas sim no conjunto de suas interações com outras políticas, considerando as desigualdades existentes (Ball, 1994). Dessa forma, é importante analisar a ampliação da educação fundamental para nove anos, considerando não apenas suas repercussóes mais imediatas no campo do currículo e das práticas pedagógicas, mas também suas repercussões mais amplas nas interações com outras políticas como, por exemplo, a educação infantil, neste caso, tendo como horizonte a questão da infância nas sociedades contemporâneas. Assim, é necessário ter em mente que o ingresso de crianças mais novas na escola obrigatória também se insere em um movimento mundial de aceleração e segmentação da infância (Mollo-Bouvier, 2005). Além disso, a educação infantil, de acordo com dados da PNAD de 2003, já absorvia $68 \%$ das crianças de 4 a 6 anos na educação infantil e no ensino fundamental. Mesmo não possuindo a informação sobre a matrícula específica das crianças de 6 anos, é fácil supor que esse índice já era superior para crianças desta faixa etária. Então, a maioria das 
crianças de 6 anos já freqüentava escola, o que deve ser considerado ao se avaliar os resultados da implementação desta política.

Em segundo lugar, é preciso destacar que grande parte dos intelectuais, que poderia levantar questōes sobre os efeitos da política em pauta, foi convocada para prestar assessoria ao MEC no processo de implementação desta política. Nesse sentido, diante da urgência para cumprir a agenda prevista pelos órgãos governamentais, estes intelectuais são privados do distanciamento necessário para a análise de uma política pública.

A partir do exposto, chega-se à primeira conclusão. Existe necessidade de trabalho de pesquisa, acompanhamento e avaliação acerca desses processos decorrentes de decisões sobre políticas públicas, especificamente de educação, que produzem impacto no cotidiano das instituições escolares e na vida das famílias com filhos em idade escolar. Isso é de fundamental importância para construir posicionamentos mais bem fundamentados sobre as questōes educacionais. Nesse sentido, é importante problematizar uma medida que aparentemente produz adesóes acaloradas. É preciso tratar o ingresso de criança de 6 anos no ensino fundamental ampliado como objeto de pesquisa, como fenômeno a ser interrogado, na perspectiva da uma análise política, sociológica e pedagógica. Sair do lugar do "sou contra" ou "sou a favor", ou quem é a favor é "democrático", quem é contra ou levanta questóes é "atrasado".

Em terceiro lugar, é importante considerar que as reformas educacionais, nos primeiros anos de sua implementação, muitas vezes apresentam resultados positivos, que tendem a decrescer e a desaparecer com os anos. Este foi o caso das reformas implantadas nos Estados Unidos dentro da proposta da tecnologia educacional, que desenvolveu projetos de ensino pelo computador e outros programas, como o "ensino por competências" e "aprendizagem para o domínio". A hipótese que se pode levantar a este respeito é de que, nos primeiros anos de implementação de uma reforma educacional, ocorre uma grande mobilização por parte dos professores, dos alunos e de suas famílias, em decorrência do interesse e entusiasmo criados pelos processos de difusão da reforma - notícias nos meios de comunicação, cursos de treinamento para docentes e difusão de material, da compra de equipamentos e de material didático, entre outros. Entusiasmo este que vai decrescendo à medida que a reforma deixa de ser algo 
"Agora seu filho entra mais cedo na escola": a criança de seis anos no ensino fundamental...

novo e objeto de divulgação e de difusão pedagógica. O que se pode extrair deste ponto de vista é que as reformas ou mudanças no sistema educacional devem se fazer acompanhar de um maior investimento no apoio à sua implementação, em um período maior de tempo. Mudanças educacionais somente se consolidam no interior da cultura escolar se for fomentado o entusiasmo que se observa no processo de sua implantação e neutralizadas as oposições que possam gerar.

Em quarto lugar, é preciso lembrar que políticas educacionais e estratégias pedagógicas não podem resultar da necessidade de solucionar problemas funcionais, como, por exemplo, a alocação de professores excedentes e o preenchimento de espaços ociosos nas escolas, devido à diminuição do efetivo de alunos, decorrência de queda de fecundidade. Isto conduz a outra conclusão, ou seja, pedagogia e política de educação não podem estar, simplesmente, submetidas à lógica da resolução de problemas funcionais.

Por último, é preciso dizer que se constata certa desqualificação da área da educação infantil no interior das políticas públicas, uma ausência de preocupação em pensar nos impactos da inclusão de crianças de 6 anos na educação fundamental, em relação às matrículas e ao acesso à educação infantil para as idades inferiores a 6 anos. Estudos recentes vêm mostrando que reformas no ensino fundamental produzem efeitos na educação infantil, que resultam em geral em diminuição e desorganização da oferta (Vieira, 2006).

Há que se reconhecer que os conhecimentos sobre os quais se baseiam as orientações e recomendaçôes do MEC e da Secretaria de Estado da Educação de Minas Gerais, sobre a inclusão das crianças de 6 anos no ensino fundamental, foram, em grande parte, produzidos no contexto da educação infantil - nas creches, nas pré-escolas e nos grupos de estudos e pesquisas da área presentes nas redes de educação básica, nas universidades e outros centros, onde destacamos o papel da ANPEd. Vale apontar aqui o documento de Orientaçōes do MEC, que se baseia nos conhecimentos acumulados no campo da educação infantil, cuja equipe de elaboração inclui especialistas da área.

A educação infantil tem sido um campo de experimentação de práticas emancipatórias, com grande circulação de idéias e projetos, que têm como objetivo uma educação que respeita os direitos da criança, tomando-a como sujeito de aprendizagem e como ator social. 
Para isso, tem se utilizado de práticas democráticas e de escuta/observação das crianças, que fazem parte da tradição e da inovação da educação pré-escolar no Brasil e no mundo (Rayna \& Brougère, 2000).

Mesmo que as práticas concretas não apresentem hegemonicamente a qualidade desejada e compatível com os conhecimentos acumulados na área dos estudos da infância, a produção teórica e algumas experiências inovadoras vêm oferecendo grandes contribuições. Contribuiçôes estas que podem fortalecer a perspectiva e as intençôes de alterar a cultura "escolarizante" do ensino fundamental e oferecer novas abordagens do processo de alfabetização. É isto, portanto, que justifica a vigilância e os esforços de pesquisa e de discussão sobre a temática em foco. Dessa maneira, recomenda-se que a educação da criança de 6 anos no ensino fundamental se nutra desta fonte, avançando cada vez mais na busca de uma educação fundamental de qualidade para todas as crianças e jovens.

Recebido e aprovado em agosto de 2006.

Notas

1. Sendo objeto de campanha publicitária, a medida foi amplamente divulgada para a mídia impressa e falada; debates sobre o tema foram promovidos na televisão e no rádio. Outdoors estavam presentes em muitos pontos de ônibus, também expostos nas traseiras dos próprios coletivos, estampando foto de uma criança sorridente, sem os dentinhos de leite superiores, marca dessa transição dos 6 para os 7 anos. Essas fotos constavam também dos folhetos que convocavam as famílias para o cadastro escolar: "agora seu filho entra mais cedo na escola".

2. Em pesquisa de opinião encomendada pela Secretaria de Estado da Educação de Minas Gerais, realizada pela Vox-Populi em dezembro de 2004, apurou-se que $95 \%$ das famílias avaliavam positivamente a inclusão de crianças a partir de 6 anos na fase introdutória do ensino fundamental. Nesta pesquisa foram ouvidos 1.104 pais/responsáveis e 885 professores, sendo $71 \%$ das redes municipais. Foi uma amostra aleatória de pais/professores de escolas de cinco Superintendências Regionais de Ensino (SRE) do interior e das três SRE que compóem a Região Metropolitana de Belo Horizonte. Ressaltamos a informação de que $68 \%$ dos filhos dos respondentes já haviam freqüentado escola/creche/jardim ou maternal, antes de 2004 . Na capital, esse resultado foi de $80 \%$.

3. Para obtenção de dados para este artigo, foi realizada uma pequena entrevista com o secretário adjunto da Secretaria de Educação do Estado de Minas Gerais, prof. João Antônio Filocre Saraiva, em 4 de agosto de 2006; e com a secretária municipal de Educação de Belo Horizonte, que também é a atual presidente da União Nacional dos Dirigentes Municipais de Educação (UNDime), profa Maria do Pilar Lacerda Almeida e Silva, em 3 de agosto de 2006.

Educ. Soc., Campinas, vol. 27, n. 96 - Especial, p. 775-796, out. 2006

Disponível em <http://www.cedes.unicamp.br> 
"Agora seu filho entra mais cedo na escola": a criança de seis anos no ensino fundamental...

4. A taxa de fecundidade total em Minas Gerais, em 2003, foi de 2,1, enquanto que no Brasil foi de 2,3. Em 1980, ela era de 4,3 nesse estado.

5. Os dados do Censo Escolar de 2005, processados pela SEE-MG, informaram a matrícula de 103.279 crianças nessa idade no ensino fundamental, sendo $65,7 \%$ matriculadas em escolas das redes municipais de ensino.

6. O cadastro escolar em Minas Gerais é feito pelo correio desde 1993, mediante apresentação de conta de luz e certidão de nascimento da criança cadastrada. Por meio da conta de luz são indicadas as escolas para o futuro aluno, de acordo com a proximidade da residência dos pais ou responsáveis.

7. Segundo a secretária municipal de Educação de Belo Horizonte, o estado havia convocado para a matrícula, em 2007, todas as crianças nascidas em 2001. Isso equivalia que as escolas aceitariam crianças que completassem 6 anos até dezembro de 2007, podendo, portanto, permanecer na fase introdutória com 5 anos durante todo o ano. Após negociaçóes, ficou estabelecido o limite de junho de 2007. Essa questão é muito relevante e tem gerado entendimentos variados, que podem acelerar a entrada de crianças mais novas na escola obrigatória. Isso levou o Conselho Nacional de Educação a definir que o primeiro ano do ensino fundamental de nove anos é para aquela criança que completa 6 anos "no início do ano letivo".

8. Com 853 municípios, Minas Gerais possui a segunda maior rede de educação do país. De acordo com o Censo Escolar de 2004 (INEP/MEC), a rede pública possuía 4.457.869 alunos, dos quais $58 \%$ encontravam-se na rede estadual e $41 \%$ nas redes municipais. A rede estadual compreendia 3.905 escolas, sendo 637 oferecendo apenas as quatro primeiras séries do ensino fundamental e 751 , as oito séries.

9. No site do MEC existe uma seção inteiramente voltada para responder dúvidas sobre o tema.

10. O Conselho Estadual de Educação se pronunciou sobre o assunto com os seguintes pareceres: Parecer n. 717/05, aprovado em 22/8/2005 e Parecer n. 289/06, aprovado em $28 / 3 / 2006$.

11. O CEALE é um dos cinco centros de alfabetização e linguagem da Rede Nacional de Formação de Professores, criada pelo Ministério de Educação em 2004, para elaborar materiais e realizar cursos para o desenvolvimento da formação continuada no Brasil. É órgão complementar da Faculdade de Educação da UfMG. No ano de 2003, a Secretaria Estadual de Educação de Minas Gerais solicitou ao CEALE a assessoria para a implantação do ciclo inicial de alfabetização, que abrange os três primeiros anos do ensino fundamental, atendendo as crianças de 6, 7 e 8 anos de idade. Tal assessoria incluiu, em primeiro lugar, a produção de material de alfabetização, leitura e escrita para este ciclo. Foi produzida uma coleção de cinco volumes que, a partir de fundamentos teóricos, oferece material instrumental para o professor, para uso em sala de aula. Esta coleção envolve orientaçōes sobre as razōes políticas da implantação do ciclo inicial de alfabetizaçăo, até a definiçẫo das capacidades/habilidades lingüísticas relativas à aprendizagem da língua materna para este ciclo, assim como orientaçóes sobre planejamento e avaliação da aprendizagem. Com base na coleção, foi organizado o curso de capacitação das equipes pedagógicas das Superintendências Regionais de Ensino (SRE), que ficaram encarregadas de orientar os professores das escolas de suas respectivas jurisdiçôes. Ao lado disto, o CEALE vem realizando a avaliação do desempenho dos alunos do ciclo inicial de alfabetizaçáo, que prevê: avaliação amostral do desempenho dos alunos de 6 anos e avaliação censitária do desempenho dos alunos no final do primeiro ciclo.

12. A respeito das contribuiçōes de Ball para a análise das políticas públicas, consultar Mainardes (2006). 


\section{Referências bibliográficas}

BALL, S.; BOWE, R.; GOLD, A. Reforming education and changing school: case studies in policy sociology. London: Routledge, 1992.

BALL, S. Educational reform: a critical and post-structural approach. Buckingham: Open University, 1994.

BARBOSA, M.C.S. As crianças devem ingressar no ensino fundamental aos seis anos? Pátio Educação Infantil, Porto Alegre, v. 1, n. 1, p. 36-37, abr./jul. 2003.

BARBOSA, M.C.S. Inquietações e perplexidades. Pátio Educação Infantil, Porto Alegre, v. 3, n. 9, p. 46-47, nov. 2005/fev. 2006.

BATISTA, A.A.G. Ensino fundamental de nove anos: um importante passo à frente. Boletim UFMG, Belo Horizonte, v. 32, n. 1522, mar. 2006.

BRASIL. Lei n. 9.394, 20 de dezembro de 1996. Estabelece as diretrizes e bases da educação nacional. Diário Oficial da União, Brasília, DF, 23 dez 1996.

BRASIL. Lei n. 9.424, 24 de dezembro de 1996. Dispõe sobre o Fundo de Manutenção e Desenvolvimento do Ensino Fundamental e de Valorização do Magistério, na forma prevista no art. $60, \$ 7^{\circ}$, do ato das disposiçôes constitucionais transitórias, e dá outras providencias. Diário Oficial da União, Brasília, DF, 26 dez. 1996.

BRASIL. Lei n. 10.172, 9 de janeiro de 2001. Aprova o Plano Nacional de Educação e dá outras providências. Diário Oficial da União, Brasília, DF, 10 jan. 2001. Disponível em: <www.mec.gov.br>

BRASIL. Lei n. 11.114, 16 de maio de 2005. Altera os arts. 6o, 30, 32 e 87 da Lei n. 9.394, de 20 de dezembro de 1996, com o objetivo de tornar obrigatório o início do ensino fundamental aos seis anos de idade. Diário Oficial da União, Brasília, DF, 17 maio 2005. Disponível em: <www.senado.gov.br>

BRASIL. Lei n. 11.274, 6 de fevereiro de 2006. Altera a redação dos arts. 29, 30, 32 e 87 da Lei n. 9.394, de 20 de dezembro de 1996, que estabelece as diretrizes e bases da educação nacional, dispondo sobre a duração de 9 (nove) anos para o ensino fundamental, com 
"Agora seu filho entra mais cedo na escola": a criança de seis anos no ensino fundamental...

matrícula obrigatória a partir dos 6 (seis) anos de idade. Diário Oficial da Uniāo, Brasília, DF, 7 fev. 2006. Disponível em: <www.senado.gov.br>

BRASIL. Conselho Nacional de Educação. Parecer CEB n. 020/1998. Consulta relativa ao ensino fundamental de nove anos. Disponível em: $<$ www.mec.gov.br >

BRASIL. Ministério da Educação. Conselho Nacional de Educação. Parecer CNE/CEB n. 06/2005. Reexamina o Parecer CNE/CEB 24/2004, que visa o estabelecimento de normas nacionais para a ampliação do Ensino Fundamental para nove anos de duração. Disponível em: $<$ www.mec.gov.br>

BRASIL. Ministério da Educação. Conselho Nacional de Educação. Parecer CNE/CEB n. 18/2005. Orientações para a matrícula das crianças de 6 (seis) anos de idade no Ensino Fundamental obrigatório, em atendimento à Lei n. 11.114, de 16 de maio de 2005, que altera os Arts. 6º 32 e 87 da Lei n. 9.394/1996. Disponível em: <www.mec.gov.br>

BRASIL. Ministério da Educação. Conselho Nacional de Educação. Resolução CNE/CEB n. 3/2005. Define normas nacionais para ampliação do Ensino Fundamental para 9 anos de duração. Disponível em: $<$ www.mec.gov.br>

BRASIL. Ministério da Educação. Secretaria de Educação Básica. Ensino fundamental de nove anos: orientaçōes gerais. Brasília, DF, 2004.

BRASIL. Ministério da Educação. Secretaria de Educação Básica. Ensino fundamental de nove anos: orientações para inclusão da criança de 6 anos de idade. Brasília, DF, 2006.

CAMPOS, M.M. Educação infantil: o debate e a pesquisa. Cadernos de Pesquisa, São Paulo, n. 101, p. 113-127, jul. 1997.

CASTRO, J.A. Financiamento da educação no Brasil. Em Aberto, Brasília, DF, v. 18, n. 74, dez. 2001.

DIDONET, V. As crianças pré-escolares no Fundo. Pátio Educação Infantil, Porto Alegre, v. 2, n. 7, nov. 1998/jan. 1999.

FARIA FILHO, L.M. Educar, instruir e civilizar: contribuição à história da educação infantil em Minas Gerais. Brasília, DF: INEP, 1995. (Documental: relatos de pesquisa, n. 24) 
LASCOUMES, P. Normes juridiques et mise en oeuvre des politiques publiques. L’Année Sociologique, Paris, v. 40, p. 43-71, 1990.

LUC, J.-N. La petite enfance à l'école: XIXe - XXe siècles. Paris: Economica, 1982.

MAINARDES, J. Abordagem do ciclo de políticas: uma contribuição para a análise de políticas educacionais. Educação \& Sociedade, Campinas, v. 27, n. 94, p. 47-69, jan./abr. 2006.

MINAS GERAIS. Decreto n. 430, de 7 de agosto de 2003. Disponível em: <www.mg.gov.br>

MINAS GERAIS. Secretaria de Estado da Educação. Resolução n. 469, de 22 de dezembro de 2003. [republicada em 3 de fevereiro de 2004, por incorreçōes na publicação anterior]. Dispõe sobre a organização e o funcionamento dos anos iniciais do ensino fundamental, com nove anos de duração, nas escolas estaduais de Minas Gerais e dá outras providências. Disponível em: <www.mg.gov.br>

MINAS GERAIS. Secretaria de Estado de Educação. Resolução n. 521, de 2 de fevereiro de 2004. Dispõe sobre a organização e o funcionamento do ensino nas escolas estaduais de Minas Gerais e dá outras providências. Disponível em: <www.mg.gov.br>

MINAS GERAIS. Secretaria de Estado de Educação. Subsecretaria de Desenvolvimento da Educação. Orientação SEE n. 01/2004. Operacionalização da Resolução SEE n. 469/2003. Disponível em: <www.mg.gov.br>

MINAS GERAIS. Conselho Estadual de Educação. Parecer n. 717/05, aprovado em 22/8/2005. Consulta oriunda da Gerência da Educação Básica da FIEMG com pedido de orientaçôes de ordem prática para cumprimento da Lei federal n. 11.114, de 16/5/2005, que estabelece a obrigatoriedade da matrícula de todos educandos a partir dos seis anos de idade. Disponível em: <www.mg.gov.br>

MINAS GERAIS. Conselho Estadual de Educação. Parecer n. 289/06, aprovado em 28/3/2006. Manifesta-se sobre a Lei federal n. 11.274, de 6 de fevereiro de 2006, que altera a Lei federal n. 11.114, de 16 de maio de 2005, e dispóe sobre a duração de 9 (nove) anos para o ensino fundamental, com matrícula obrigatória aos seis anos de idade. Disponível em: <www.mg.gov.br> 
"Agora seu filho entra mais cedo na escola": a criança de seis anos no ensino fundamental...

MOLLO-BOUVIER, S. Transformação dos modos de socialização das crianças: uma abordagem sociológica. Educação \& Sociedade, Campinas, v. 26, n. 91, p. 391-403, maio/ago. 2005.

MOSS, P. "Primo pobre" ou sócio igualitário: discutindo a educação infantil na Inglaterra. Pátio Educação Infantil, Porto Alegre, v. 1, n. 3, p. 43-44, dez. 2003/mar. 2004.

RAYNA, S.; BROUGÈRE, G. (Coord.). Traditions et innovations dans l'education préscolaire: perspectives internationales. Paris: INRP, 2000.

VIEIRA, L.M.F. Education de la petite enfance dans la législation éducationnelle brésilienne $d u X X^{\text {eme }}$ siècle: approche historique de l'état de Minas Gerais (1908-2000). 2006. Tese (Doutorado) - Université René-Descartes, Sciences Humaines, Paris. 